\title{
SBA-15 mesoporous silica modified with rhodium by MDD method and its catalytic role for $\mathrm{N}_{2} \mathrm{O}$ decomposition reaction
}

\author{
Lucjan Chmielarz • Piotr Kuśtrowski • Marek Drozdek • \\ Małgorzata Rutkowska • Roman Dziembaj • Marek Michalik • \\ Pegie Cool • Etienne F. Vansant
}

Published online: 7 July 2010

(c) The Author(s) 2010. This article is published with open access at Springerlink.com

\begin{abstract}
SBA-15 mesoporous silicas modified with rhodium were studied as catalysts for the $\mathrm{N}_{2} \mathrm{O}$ decomposition reaction. Rhodium was deposited on SBA-15 by the Molecular Designed Dispersion (MDD) method using Rh(acac) $)_{3}$ as a precursor of active phase. The same method was used for the deposition of $\mathrm{Cu}, \mathrm{Fe}, \mathrm{Al}$ and Ti. The SBA-15 support modified with metals were characterized with respect to metal loading (EPMA), structure (XRD), texture (BET), morphology (SEM), Rh dispersion (oxygen chemisorption), surface acidity (pyridine adsorption) and chemical nature of introduced copper and iron species (UV-vis-DRS). The rhodium-containing SBA-15 samples were found to be active catalysts for the $\mathrm{N}_{2} \mathrm{O}$ decomposition reaction. Deposition of $\mathrm{Al}$ on the Rh-loaded catalyst increased its activity. An opposite effect was observed for the samples modified with $\mathrm{Cu}$ and $\mathrm{Fe}$.
\end{abstract}

Keywords $\mathrm{N}_{2} \mathrm{O}$ decomposition - SBA-15 - Rhodium . MDD method

L. Chmielarz $(\varangle) \cdot$ P. Kuśtrowski · M. Drozdek

M. Rutkowska · R. Dziembaj

Faculty of Chemistry, Jagiellonian University, Ingardena 3, 30-060 Kraków, Poland

e-mail: chmielar@chemia.uj.edu.pl

M. Michalik

Institute of Geological Sciences, Jagiellonian University,

Oleandry 2a, 30-063 Kraków, Poland

P. Cool - E. F. Vansant

Department of Chemistry, University of Antwerp,

Universiteitsplein 1, 2610 Wilrijk, Belgium

\section{Introduction}

Nitrous oxide pollution abatement is an important environmental problem due to the high greenhouse potential and its impact in the depletion of ozone layer [1,2]. The concentration of $\mathrm{N}_{2} \mathrm{O}$ in the atmosphere increases annually by about $0.2-0.3 \%$ and is caused mainly by anthropogenic activities [3]. Chemical industry (e.g. production of nitric acid, adipic acid, caprolactam) is one of the major emitters of nitrous oxide [4]. Nowadays, the catalytic decomposition of $\mathrm{N}_{2} \mathrm{O}$ to nitrogen and oxygen seems to be the most promising way for the limitation of nitrous oxide emissions. Rhodium has been found to be an active component for $\mathrm{N}_{2} \mathrm{O}$ decomposition catalysts [5-9]. Kondratenko et al. [5] have reported a high activity of Pt-Rh alloys in the nitrous oxide decomposition. Oi et al. [6] have studied catalytic activity of rhodium deposited on various supports $\left(\mathrm{ZnO}, \mathrm{CeO}_{2}\right.$ and $\left.\mathrm{ZSM}-5\right)$. Among the studied catalytic systems, the best results were obtained for the $\mathrm{Rh} / \mathrm{ZnO}$ catalyst which was significantly more active than the Co-Al oxide system as well as Cu-ZSM-5. On the other hand, Doi et al. [8] have studied the reaction of $\mathrm{N}_{2} \mathrm{O}$ decomposition over noble metals ( $\mathrm{Rh}, \mathrm{Pt}, \mathrm{Pd}$ ) deposited on $\mathrm{Al}_{2} \mathrm{O}_{3}$. The $\mathrm{Rh} / \mathrm{Al}_{2} \mathrm{O}_{3}$ catalytic system was found to be significantly more active and stable than the other studied catalysts. Haber et al. [9] have tested alkali metal cations $(\mathrm{Li}, \mathrm{Na}, \mathrm{K}, \mathrm{Cs})$ as promoters of $\mathrm{Rh} / \mathrm{Al}_{2} \mathrm{O}_{3}$ catalysts. It was shown that deposition of alkali metals significantly increased the rhodium dispersion. On the other hand, the dispersion of rhodium was found to be one of the key parameters influencing catalytic performance. The mechanism of $\mathrm{N}_{2} \mathrm{O}$ decomposition over unsupported rhodium catalyst was studied by Tanaka et al. [7]. They suggested that desorption of oxygen, which is the rate determining step of nitrous oxide 
decomposition, proceeds mainly by recombination with another ad-atom or with another $\mathrm{N}_{2} \mathrm{O}$ molecule.

The aim of the presented studies was evaluation of the catalytic performance of rhodium dispersed on high surface area, mesoporous SBA-15-type silica. This support is characterized by a uniform hexagonal ordering of channels with diameters in the range of 5-30 nm [10]. Since SBA-15 possesses thick pore walls, its thermal and hydrothermal stability is higher compared to MCM-41 [11]. Such features may provide a high potential of SBA-15 as a support for catalytic applications. The Molecular Designed Dispersion (MDD) [12] method, guarantying high dispersion of metals, was used for their deposition on the SBA-15 surface. This method consists of two steps. In a first step, metalorganic complex reacts with the silanol group of support whereas in a second step, the adsorbed surface complex is thermally decomposed in an oxygen containing atmosphere, yielding the highly dispersed metal oxide species deposited on the silica surface. Various transition metals were successfully deposited on different types of mesoporous silica [13, 14]. Catalysts obtained by the MDD method were found to be more active than that obtained by impregnation methods in various processes including e.g. DeNOx [15-17] and the oxidative dehydrogenation of hydrocarbons $[18,19]$.

\section{Experimental}

\subsection{Samples preparation}

SBA-15, which was used as a support for metal active phases depositions, was prepared using $4 \mathrm{~g}$ of Pluronic P123 triblock copolymer surfactant $\left(\mathrm{EO}_{20}-\mathrm{PO}_{70}-\mathrm{EO}_{20}\right)$ dissolved in a water solution of $\mathrm{HCl}$ (2 M). Subsequently, a suitable amount of tetraethyl orthosilicate (TEOS) was added. The mixture was stirred at $45^{\circ} \mathrm{C}$ for $8 \mathrm{~h}$ and then aged at $80{ }^{\circ} \mathrm{C}$ for $15 \mathrm{~h}$. The solid product was separated by filtration, washed with distillated water and dried at room temperature. Finally, the sample was calcined in an air atmosphere at $550{ }^{\circ} \mathrm{C}$ with a heating rate of $1{ }^{\circ} \mathrm{C} / \mathrm{min}$ and an isothermal period of $6 \mathrm{~h}$. Detailed description of SBA-15 synthesis as well as its characterization was presented in our previous paper [14].

Metal oxides were deposited on the SBA-15 surface by the molecular designed dispersion (MDD) method using suitable acetylacetonate complexes. The MDD method consists of two steps. In a first step, metal acetylacetonate complex $\left(\left(\mathrm{M}^{n+}(\mathrm{acac})_{n}\right)\right.$ reacts with the hydroxyl group of a silica support. In a second step, the adsorbed surface complex is decomposed in an oxygen containing atmosphere at elevated temperatures, yielding the supported transition metal oxide catalysts [20].
An amount of $0.40 \mathrm{mmol}$ of $\mathrm{Cu}(\mathrm{acac})_{2}, \mathrm{Fe}(\mathrm{acac})_{3}$, $\mathrm{TiO}(\mathrm{acac})_{2}$ or $\mathrm{Al}(\mathrm{acac})_{3}$ was dissolved in $100 \mathrm{~cm}^{3}$ of zeolite dried toluene. Prior to the deposition process, SBA-15 was dried at $200{ }^{\circ} \mathrm{C}$ for $2 \mathrm{~h}$. Subsequently, the mesoporous support $(1 \mathrm{~g})$ was added to the solution of acetylacetonate complex. Then, the suspension was stirred for $1 \mathrm{~h}$. After reaction the modified SBA-15 sample was separated by filtration, washed 5 times with toluene $\left(25 \mathrm{~cm}^{3}\right)$ and vacuum dried. All these operations were performed in dry atmosphere. The samples modified with acetylacetonate complexes were calcined in an air atmosphere at $550{ }^{\circ} \mathrm{C}$ for $6 \mathrm{~h}$. In the next step, rhodium was deposited on the SBA-15 supports modified with metal oxides as well as on the pure mesoporous silica. Acetylacetonate complex of rhodium$\mathrm{Rh}(\mathrm{acac})_{3}$-was deposited on the surface of the mesoporous SBA-15 silica by the MDD method as well. The loading of the samples with noble metal was regulated using toluene solutions containing various concentrations $(0.05,0.10$, $0.20,0.30 \mathrm{mmol} / \mathrm{g}$ ) of $\mathrm{Rh}(\mathrm{acac})_{3}$. Subsequently, the modified samples were washed, dried and calcined according to the procedure applied for the deposition of the other metals. The Rh-containing samples are denoted as RhX-SBA-15, where $\mathrm{X}$ is the concentration of $\mathrm{Rh}(\mathrm{acac})_{3}$ in the solution used for the noble metal deposition.

The reference sample was obtained by the incipient wetness method using a methanol solution of $\mathrm{Rh}(\mathrm{acac})_{3}$. The impregnated sample was dried sample at $120^{\circ} \mathrm{C}$ overnight and calcined at $550{ }^{\circ} \mathrm{C}$ for $6 \mathrm{~h}$. The sample obtained by the impregnation method is denoted as Rh-imp-SBA-15.

As reference catalysts, two other samples were used: (1) mixed $\mathrm{Co}-\mathrm{Mg}-\mathrm{Al}$ metal oxide obtained from hydrotalcite (calcination at $800{ }^{\circ} \mathrm{C}$ ). The atomic $\mathrm{Co} / \mathrm{Mg} / \mathrm{Al}$ ratio is $15 /$ $56 / 29$ and surface area about $76 \mathrm{~m}^{2} / \mathrm{g}$. Detailed description of the synthesis of this sample as well as its characteristics was presented in our previous paper [21]; (2) zeolite Y modified with iron by ion-exchange method using aqueous solution of $\mathrm{Fe}\left(\mathrm{NO}_{3}\right)_{3}$. Zeolite, supplied by Azko Nobel, Eka Chemicals (Sweden), is characterized by the $\mathrm{Si} /$ Al molar ratio of 16 . The iron loading in catalysts is $1.2 \mathrm{wt} \%$, while the surface area of the modified zeolite is $741 \mathrm{~m}^{2} / \mathrm{g}$.

\subsection{Characterization methods}

The concentration of transition metal oxide deposited on the support was determined by electron microprobe analysis (EPMA, JEOL Superprobe 733).

Porosity and surface area studies were performed using a Quantachrome Autosorb 1 MP automated gas adsorption system. The calcined samples were outgassed overnight at $200{ }^{\circ} \mathrm{C}$ under vacuum prior to $\mathrm{N}_{2}$ adsorption at $-196{ }^{\circ} \mathrm{C}$. Surface areas were calculated according to the BET 
equation whereas pore size distributions were derived from the adsorption isotherm using the BJH model. The total pore volume was determined by means of the total amount of adsorbed nitrogen at $P / P_{0}=0.98$.

Scanning electron microscope (SEM) images were obtained on a HITACHI S-4700 equipped with microanalysis system NORAN Vantage operated an accelerating voltage of $10 \mathrm{kV}$.

The X-ray diffraction patterns of the raw clay as well as its modifications were obtained with a Philips X'Pert APD diffractometer using $\mathrm{CuK}_{\alpha}$ radiation.

Photoacoustic infrared spectra (FTIR-PAS) of the modified SBA-15 samples were measured on a Nicolet 20 SX spectrometer equipped with a McClelland photoacoustic cell. The spectra (2000 scans) were collected in the range of 400-4,000 $\mathrm{cm}^{-1}$ with a resolution of $4 \mathrm{~cm}^{-1}$. The FTIR-PAS spectrometer was placed in an isolated bench, which was purged with pure nitrogen to ensure that the sample was completely dried.

The dispersion of rhodium was determined by oxygen chemisorption. The Rh-containing samples of $50 \mathrm{mg}$ were reduced in a flow of hydrogen at temperature $500{ }^{\circ} \mathrm{C}$ for $2 \mathrm{~h}$. Then, temperature decreased to $40{ }^{\circ} \mathrm{C}$ and the sample was purged in a flow of pure helium for $15 \mathrm{~min}$. Subsequently, the pulses of oxygen were introduced into the reactor. The analysis of gases was performed by a TCD detector (Valco) connected directly to the reactor outlet. For the determination of the noble metal dispersion it was assumed that one oxygen atom $(\mathrm{O})$ reacts with one atom of $\mathrm{Rh}[22,23]$.

The nature of the surface acidic sites was studied by FTIR measurements of the samples preadsorbed with pyridine. Transmission IR spectra were recorded using wafers in the form of self-supporting pellets of the catalyst powder. The pellet was placed in an IR cell equipped with $\mathrm{KBr}$ windows properly designed to carry out spectroscopic measurements at different temperatures. The cell was connected to a vacuum line allowing all thermal treatments and adsorption-desorption experiments to be carried out in situ. Prior to pyridine adsorption, the sample was outgassed overnight at $200{ }^{\circ} \mathrm{C}$ under vacuum. Then, the cell was cooled to room temperature and the catalyst was allowed to react with pyridine for $1 \mathrm{~h}$. FTIR spectra were recorded on a Nicolet 20SXB spectrometer at different desorption temperatures. 200 scans were taken with a resolution of $4 \mathrm{~cm}^{-1}$.

The chemical nature of deposited transition metals was studied by UV-vis-DR spectroscopy. The measurements were performed in the range of $200-900 \mathrm{~nm}$ with a resolution of $2 \mathrm{~nm}$ for the samples $(2 \mathrm{wt} \%)$ diluted in $\mathrm{KBr}$ using a Nicolet Evolution 500 spectrophotometer.

\subsection{Catalytic tests}

The modified SBA-15 samples were tested as catalysts for $\mathrm{N}_{2} \mathrm{O}$ decomposition. Catalytic studies were carried out under atmospheric pressure in a fixed-bed flow reactor (i.d., $7 \mathrm{~mm}$; 1., $240 \mathrm{~mm}$ ). The reactant concentrations were continuously measured using a quadrupole mass spectrometer (VG Quartz) connected to the reactor via a heated line. Prior to the reaction, each sample of the catalyst $(100 \mathrm{mg})$ was outgassed in a flow of pure helium at $450{ }^{\circ} \mathrm{C}$ for $1 \mathrm{~h}$. The composition of the gas mixture at the reactor inlet was $\left[\mathrm{N}_{2} \mathrm{O}\right]=0.5 \%,\left[\mathrm{O}_{2}\right]=3.5 \%$ and $[\mathrm{He}]=96 \%$. The catalytic tests were also performed using the wet reaction mixture $\left(\left[\mathrm{N}_{2} \mathrm{O}\right]=0.5 \%, \quad\left[\mathrm{O}_{2}\right]=3.5 \%, \quad\left[\mathrm{H}_{2} \mathrm{O}\right]=5 \% \quad\right.$ and $[\mathrm{He}]=91 \%$ ). In both cases the total flow rate of the reaction mixture was $40 \mathrm{~mL} / \mathrm{min}$. The reaction was studied at temperatures ranging from 100 to $550{ }^{\circ} \mathrm{C}$. The intensities of the mass lines corresponding to all reactants and possible products were measured at a given temperature for at least $30 \mathrm{~min}$ after the reaction had reached a steady-state. The signal of the helium line served as the internal standard to compensate possible small fluctuations in the operating pressure. The sensitivity factors of the analyzed lines were calibrated using commercial mixtures of gases.

\section{Results and discussion}

The grafting of acetylacetonate complexes on the SBA-15 mesoporous silica surface was proven by the PAS-FTIR measurements. Figure 1 shows the spectra of the samples modified with $\mathrm{Rh}(\mathrm{acac})_{3}$ complex (non calcined) and for comparison also the spectra recorded for the pure SBA-15 support. For the samples modified with $\mathrm{Rh}(\mathrm{acac})_{3}$ new bands at around 1,380, 1,525 and $1,570 \mathrm{~cm}^{-1}$ appeared. The symmetric deformation vibrations of $\mathrm{CH}_{3}$ groups of acetylacetonate ligand are represented by the peak centered at $1,380 \mathrm{~cm}^{-1}$. The band at $1,525 \mathrm{~cm}^{-1}$ is assigned to asymmetric stretching vibration of ring $\mathrm{C}=\mathrm{C}=\mathrm{C}$ species, while the peak centered at $1,570 \mathrm{~cm}^{-1}$ is attributed to symmetric stretching vibrations of ring $\mathrm{C}=\mathrm{O}$ groups in acetylacetonate ligands $[13,15]$. The appearance of the bands characteristic for acetylacteonate vibrations is accompanied by the change in the intensity of bands characteristic of silanol groups. The band, related to isolated hydroxyl groups, is present in the spectrum of the pure SBA-15 support at $3,745 \mathrm{~cm}^{-1}$. The modification of SBA-15 with $\mathrm{Rh}(\mathrm{acac})_{3}$ complex resulted in a decrease in the intensity of this band and an appearance of wide peak centered at about $3,400 \mathrm{~cm}^{-1}$ specific for the hydroxyl groups involved in H-bonding [15]. The obtained results 


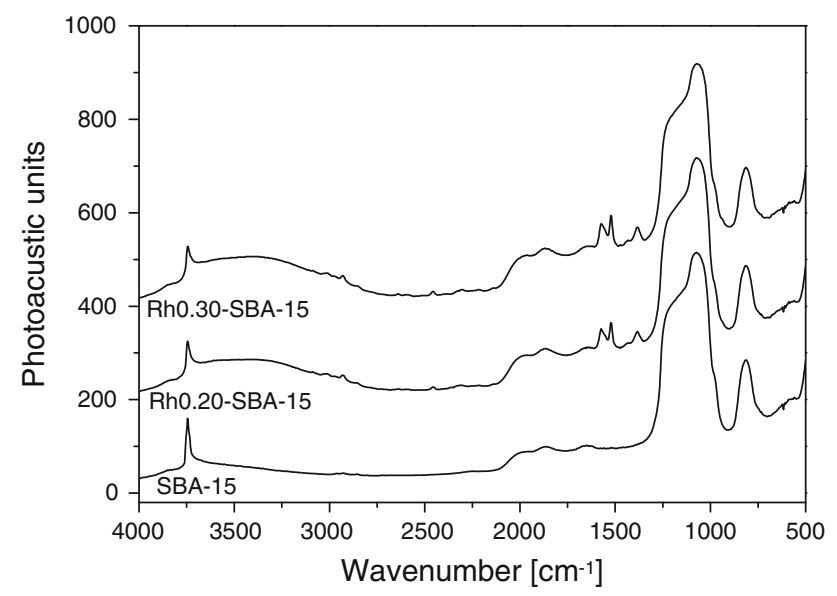

Fig. 1 PAS-FTIR spectra of SBA-15 and its modifications with $\mathrm{Rh}(\mathrm{acac})_{3}$

indicate that the proton of the surface silanol group interacts with acetylacetonate ligand. It should be noticed that only part of surface hydroxyl groups is involved in the formation of $\mathrm{H}$-bond with $\mathrm{Rh}(\mathrm{acac})_{3}$ complexes. The mechanisms of the interaction of acetylacetonate complexes of various metals with the surface of mesoporous silicas were presented in our previous papers [13, 15, 24].

The XRD patterns of SBA-15 and its modification with rhodium (Rh0.30-SBA-15) are presented in Fig. 2. The XRD patterns show the characteristic two-dimensional hexagonal structure $(p 6 \mathrm{~mm})$, where each pore is further surrounded by six pores [25]. It should be noted that deposition of rhodium did not produced any new reflexes characteristic of this metal or its compounds [26]. Therefore, it could be concluded that the size of rhodium species deposited on the SBA-15 support is below detection level of the XRD method.

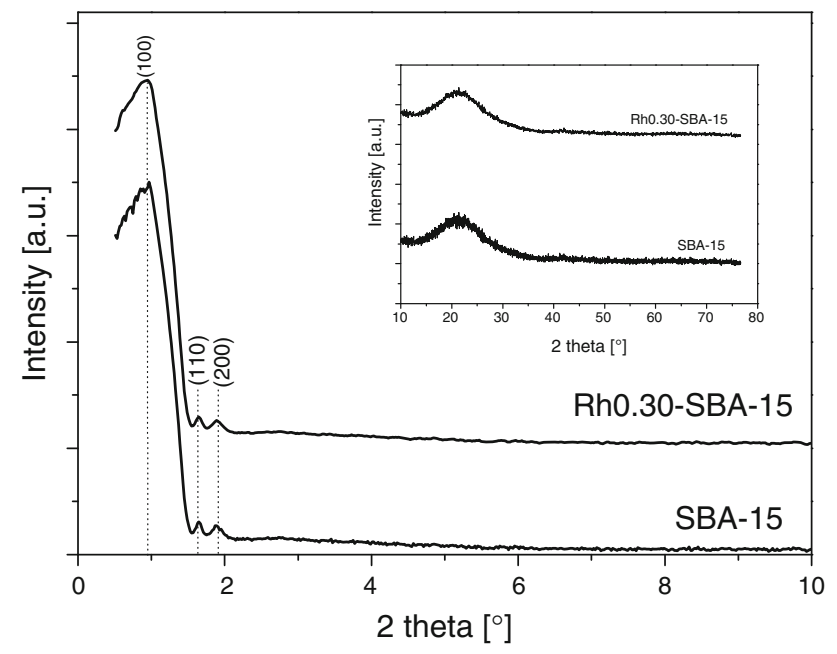

Fig. 2 XRD patterns of SBA-15 and its modification with rhodium (Rh-0.30-SBA-15)

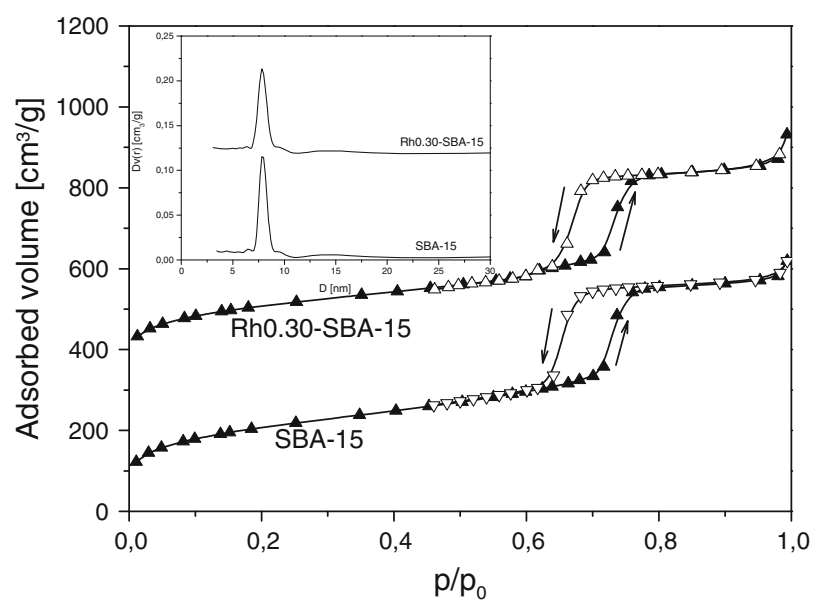

Fig. $3 \mathrm{~N}_{2}$ adsorption-desorption isotherms of SBA-15 and its modification with rhodium (Rh-0.30-SBA-15)

The nitrogen adsorption-desorption isotherm and $\mathrm{BJH}$ pore size distribution determined for SBA-15 and its modification with rhodium (Rh0.30-SBA-15) are presented in Fig. 3. The both samples exhibited type IV adsorptiondesorption isotherm, which is typical of mesoporous materials. The samples are characterized by the uniform pore size distribution with the most possible diameter of $7.8 \mathrm{~nm}$.

The content of deposited metals and textural parameters of the SBA-15 based samples (after calcination) are shown in Table 1 . The pure SBA-15 support was characterized by a relatively high surface area and pore volume of $580 \mathrm{~m}^{2} / \mathrm{g}$ and $0.61 \mathrm{~cm}^{3} / \mathrm{g}$, respectively, which slightly decreased after the rhodium deposition by the MDD method. Impregnation of the silica support with rhodium (sample Rh-imp-SBA-15) resulted in a decrease of surface area to $505 \mathrm{~m}^{2} / \mathrm{g}$. A significant decrease in the textural parameters was observed also after the deposition of other metals, probably due to their higher loading.

Figure 4 presents the correlation between the concentration of $\mathrm{Rh}(\mathrm{acac})_{3}$ in the solutions used for the modification of the mesoporous support and the Rh-loading in the samples. It should be noted that for the solutions containing 0.05 and $0.10 \mathrm{mmol}$ of $\mathrm{Rh}(\mathrm{acac})_{3}$, a majority of rhodium complex molecules was bounded to the surface of the mesoporous support whereas the effectiveness of the rhodium deposition on SBA-15 was significantly lower for more concentrated solutions of $\mathrm{Rh}(\mathrm{acac})_{3}$.

The MDD method used for the deposition of metals on the surface of the mesoporous silica support guaranteed their high dispersion. Figure 5 presents the correlation between the Rh-loading and dispersion of this noble metal on SBA-15. It should be noted that the increasing Rhloading resulted in a gradual decrease of the rhodium dispersion. However, for the highest loading of noble metal 
Table 1 Textural parameters and metals loading in SBA-15 materials

\begin{tabular}{|c|c|c|c|c|c|c|}
\hline Sample & $\mathrm{Rh}(\mathrm{wt} \%)$ & $\mathrm{Ti}$ or $\mathrm{Al}(\mathrm{wt} \%)$ & $\mathrm{Cu}$ or $\mathrm{Fe}(\mathrm{wt} \%)$ & $S_{\mathrm{BET}}\left(\mathrm{m}^{2} / \mathrm{g}\right)$ & $V_{\mathrm{p}}\left(\mathrm{cm}^{3} / \mathrm{g}\right)$ & $D(\mathrm{~nm})$ \\
\hline SBA-15 & & & & 580 & 0.61 & 7.8 \\
\hline Rh0.05-SBA-15 & 0.40 & & & 575 & 0.60 & 7.8 \\
\hline Rh0.10-SBA-15 & 0.86 & & & 563 & 0.57 & 7.8 \\
\hline Rh0.20-SBA-15 & 1.10 & & & 554 & 0.55 & 7.8 \\
\hline Rh0.30-SBA-15 & 1.49 & & & 539 & 0.53 & 7.8 \\
\hline Rh-imp-SBA-15 & 1.52 & & & 505 & 0.48 & 7.8 \\
\hline Ti-SBA-15 & & 4.57 [Ti] & & 518 & 0.55 & 7.8 \\
\hline Al-SBA-15 & & $1.17[\mathrm{Al}]$ & & 555 & 0.58 & 7.8 \\
\hline $\mathrm{Cu}-\mathrm{SBA}-15$ & & & $1.65[\mathrm{Cu}]$ & 572 & 0.60 & 7.8 \\
\hline Fe-SBA-15 & & & $2.20[\mathrm{Fe}]$ & 543 & 0.59 & 7.8 \\
\hline Rh-Ti-SBA-15 & 0.80 & $4.40[\mathrm{Ti}]$ & & 497 & 0.45 & 7.8 \\
\hline Rh-Al-SBA-15 & 0.89 & $1.00[\mathrm{Al}]$ & & 531 & 0.52 & 7.8 \\
\hline $\mathrm{Rh}-\mathrm{Cu}-\mathrm{SBA}-15$ & 0.67 & & $1.16[\mathrm{Cu}]$ & 524 & 0.51 & 7.8 \\
\hline Rh-Fe-SBA-15 & 0.62 & & $1.49[\mathrm{Fe}]$ & 509 & 0.48 & 7.8 \\
\hline
\end{tabular}

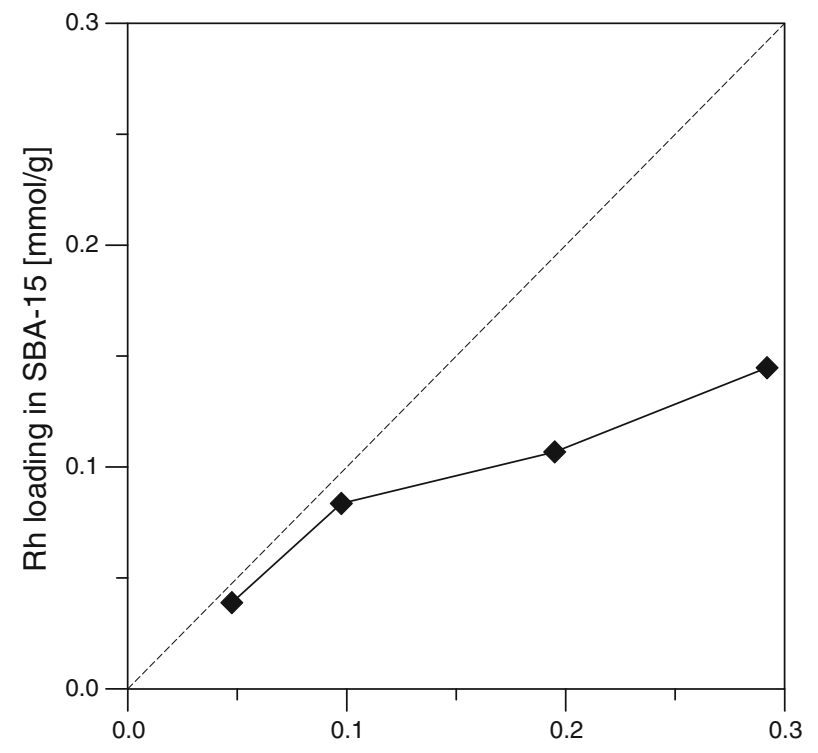

Concentration of $\mathrm{Rh}(\mathrm{acac}) 3$ in solution [mmol/100 ml]

Fig. 4 Correlation between concentration of $\mathrm{Rh}(\mathrm{acac})_{3}$ in solutions and the loading of the samples with rhodium

deposited by the MDD method its dispersion did not drop below $70 \%$. Deposition of similar amount of rhodium by the impregnation method resulted in its significant lower dispersion, which did not exceed $60 \%$.

SEM image (Fig. 6a) reveals that the parent SBA-15 sample consists of wheat-like macrostructures aggregated with rope-like domains. After rhodium deposition (Fig. 6b) a partial degradation of macroscopic structure was observed. It should be noted that any rhodium clusters have not been found on the silica surface, what suggest a very high dispersion of this metal in the SBA-15 sample.

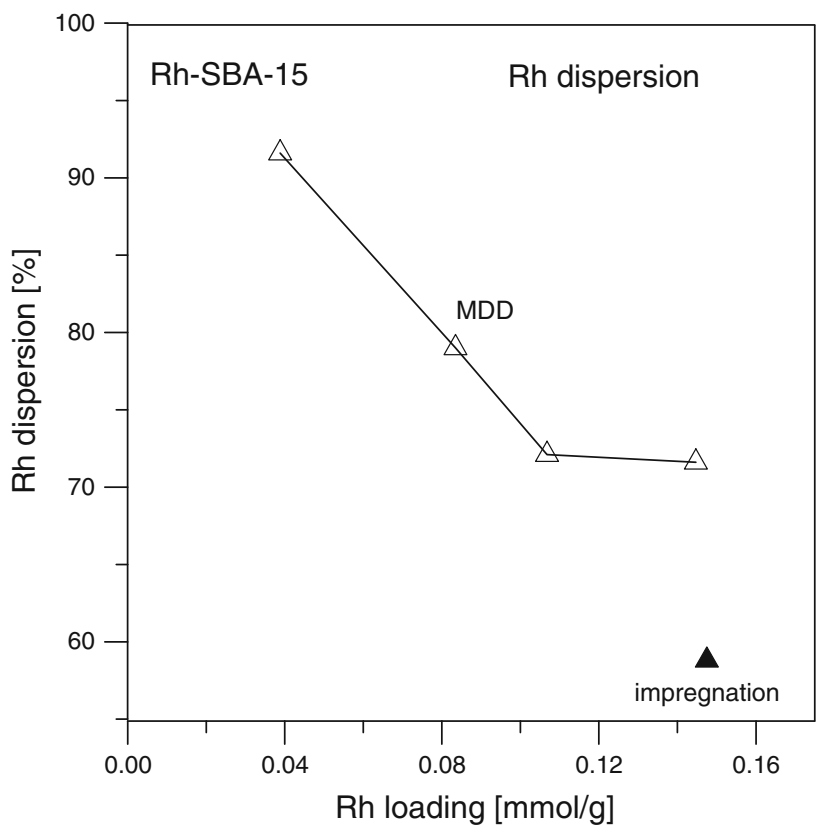

Fig. 5 Correlation between loading and dispersion of rhodium in the SBA-15 samples

The surface acidity of the SBA-15 support was generated by the deposition of aluminium and titanium oxides. The nature of acidic sites was studied by pyridine adsorption. Figures 7 present the FTIR spectra in the region of $1,400-1,700 \mathrm{~cm}^{-1}$ after adsorption of the probe molecule on the SBA-15 materials. Pure SBA-15 mesoporous silica shows a small peak at about $1,445 \mathrm{~cm}^{-1}$, which is attributed to hydrogen-bonded pyridine [27, 28]. However, outgassing of the sample at temperature $250{ }^{\circ} \mathrm{C}$ resulted in a disappearance of this band. The spectrum recorded for the Al-containing sample after the sorption of 

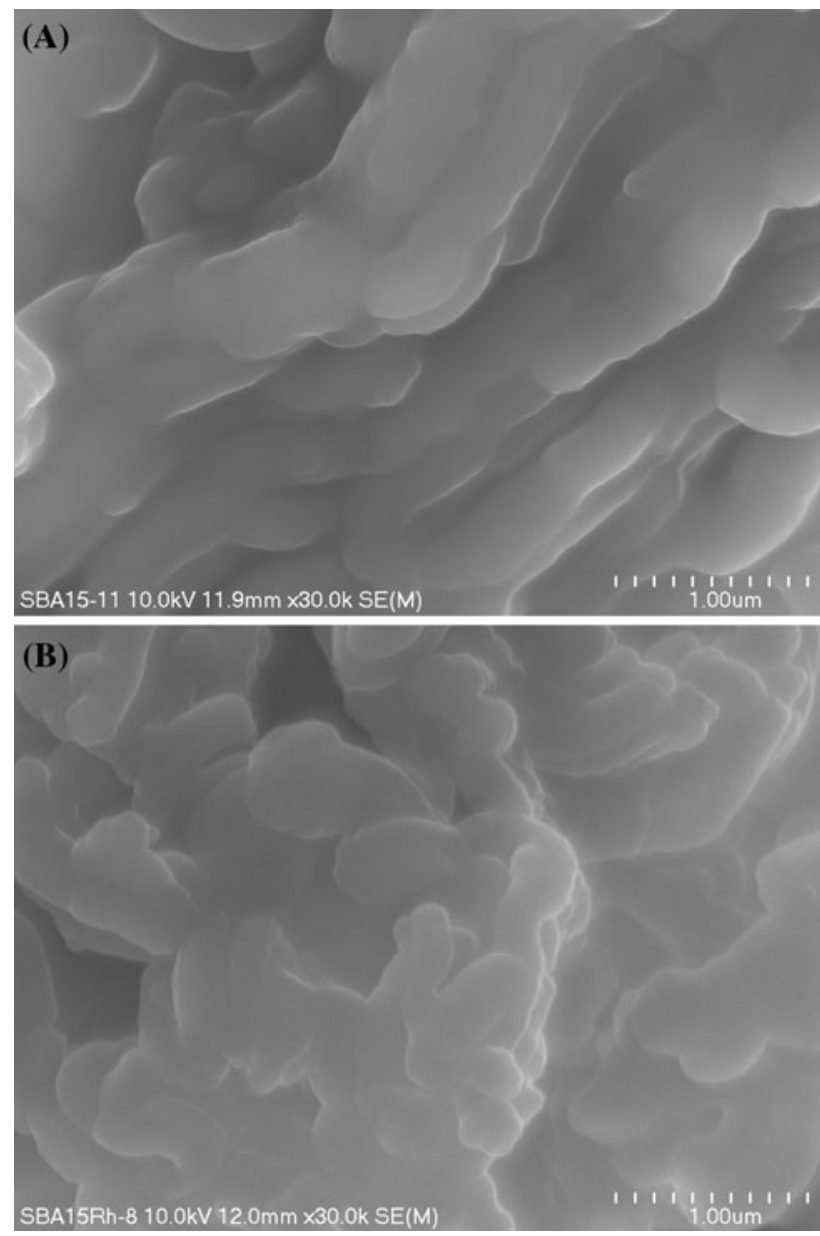

Fig. 6 SEM images of SBA-15 (a) and its modification with rhodium-Rh-0.30-SBA-15 (b)

pyridine and outgassing at $100{ }^{\circ} \mathrm{C}$ contains three well resolved maxima at about $1,545,1,490$ and $1,455 \mathrm{~cm}^{-1}$ related to the chemisorbed forms of pyridine. The bands at 1,545 and $1,455 \mathrm{~cm}^{-1}$ are assigned to pyridine adsorbed on the Brönsted and Lewis acidic sites, respectively [29, 30]. The peak at $1,490 \mathrm{~cm}^{-1}$ is attributed to the adsorbed pyridine species on both Brönsted and Lewis acidic centres. An increase in outgasing temperature to $175^{\circ} \mathrm{C}$ resulted in a decrease of intensity of the band centred at $1,455 \mathrm{~cm}^{-1}$ and an appearance of new maxima at about $1,445 \mathrm{~cm}^{-1}$. This new band is characteristic of hydrogen-bonded pyridine $[27,31]$. The bands related to pyridine adsorbed on both Brønsted and Lewis acidic centres as well as hydrogen-bonded pyridine are present in the spectrum of the sample outgassed at temperature $350{ }^{\circ} \mathrm{C}$. Therefore, it could be concluded that acidic sites generated by the deposition of aluminium on the SBA-15 surface are characterized by a relatively high acidic strength. Modification of SBA-15 with titanium oxide resulted in formation of Lewis acidic sites (band at $1,455 \mathrm{~cm}^{-1}$ ), which show
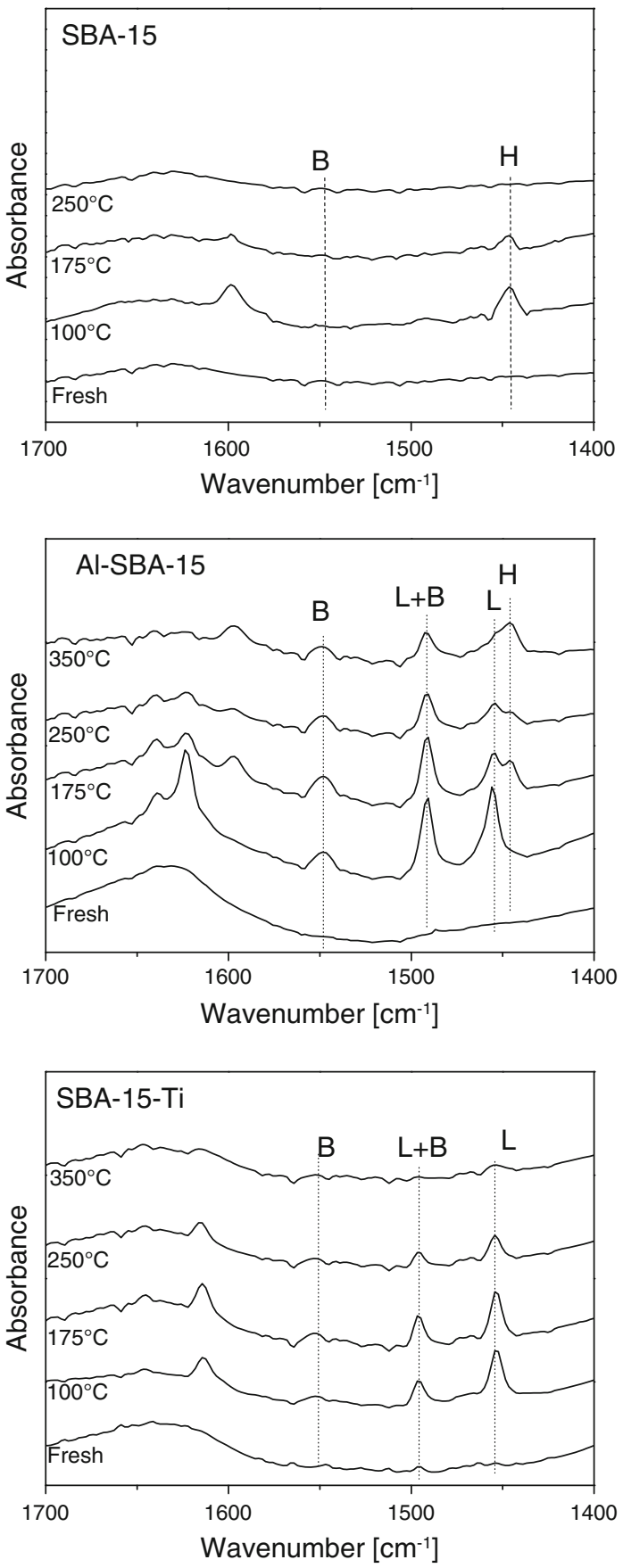

Fig. 7 FTIR spectra of the SBA-15 based catalysts preadsorbed with pyridine. $\mathrm{L}, \mathrm{B}$ and $\mathrm{H}-$ bands related to the presence of Lewis and Brönsted acid sites as well as hydrogen bonded pyridine, respectively

significantly lower acidic strength comparing to sites present in the Al-containing sample.

In our previous studies copper and iron deposited on SBA-15 have been found to be catalytically active components in the decomposition of $\mathrm{N}_{2} \mathrm{O}$ [28]. Therefore, we decided to test the catalysts containing simultaneously rhodium and these transition metals. The chemical nature of transition metals species deposited on the surface of 


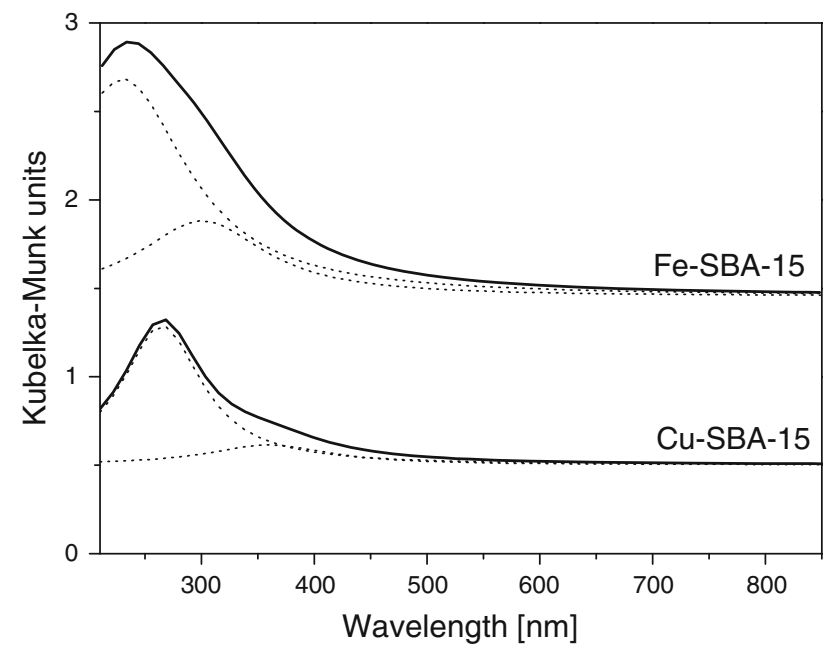

Fig. 8 UV-vis-DR spectra of mesoporous SBA-15 silica modified with copper and iron

SBA-15 was studied by UV-vis-DR spectroscopy. Results of these studies are shown in Fig. 8. The original spectrum, recorded for the $\mathrm{Cu}$-containing sample, was fitted by two bands. The first maximum at about $265 \mathrm{~nm}$ is related to charge-transfer between mononuclear $\mathrm{Cu}^{2+}$ ion and oxygen whereas the peak at around $365 \mathrm{~nm}$ can be ascribed to charge-transfer between cluster $\mathrm{Cu}^{2+}$ and oxygen in $[\mathrm{Cu}-$ $\mathrm{O}-\mathrm{Cu}]_{n}$ surface species $[13,32,33]$. The spectra recorded
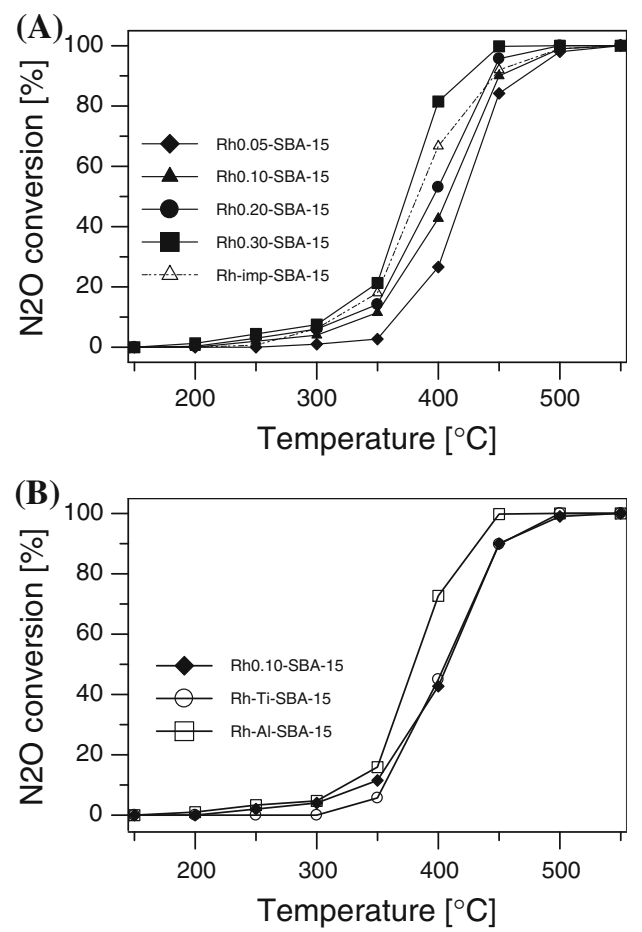

Fig. 9 Results of catalytic tests for a series of the rhodium modified SBA-15 (a), Rh-Ti-SBA-15 and Rh-Al-SBA-15 (b), Rh-Fe-SBA-15 and Rh-Cu-SBA-15 (c) as well as the comparison of catalytic activity for the Fe-containing sample were fitted with two bands centered at about 230 and $300 \mathrm{~nm}$, respectively. The first maximum is related to the isolated $\mathrm{Fe}^{3+}$ cations, while the second one corresponds to small oligonuclear $(\mathrm{FeO})_{n}$ species $[13,34,35]$. Therefore, it could be concluded that transition metals deposited on the surface of SBA-15 are present in the form of isolated cations as well as oligomeric metal oxide species. Bands characteristic for bulky metal oxide clusters were not found.

The results of the studies of SBA-15 modified with rhodium in the role of catalysts for $\mathrm{N}_{2} \mathrm{O}$ decomposition are presented in Fig. 9a. The conversion of $\mathrm{N}_{2} \mathrm{O}$ began at temperature as low as $200{ }^{\circ} \mathrm{C}$. At higher temperatures the performance of catalysts depended on Rh-loading. Increasing loading of rhodium led to an increase in activity of the catalysts. For the most active catalyst (Rh0.30-SBA15), the total $\mathrm{N}_{2} \mathrm{O}$ conversion was obtained at $450{ }^{\circ} \mathrm{C}$ whereas for the other catalysts complete elimination of nitrous oxide from reaction mixture was achieved at temperatures higher by at least $50{ }^{\circ} \mathrm{C}$. It should be noted that activity of the Rh0.30-SBA- 15 catalyst prepared by the MDD method was significantly higher than that measured for the sample obtained by the impregnation method (Rhimp-SBA-15) though both these catalysts contain the similar loading of rhodium (1.49 and $1.52 \mathrm{wt} \%$, respectively). The difference in the catalytic performance is probably related to various dispersion of the catalytically
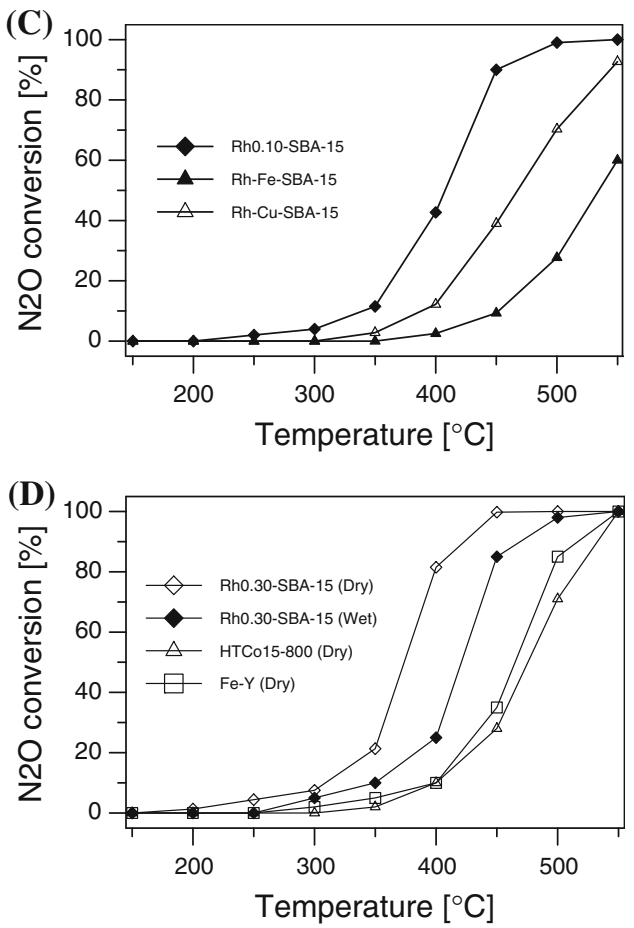

of Rh0.30-SBA-15 in flow of wet and dry reaction mixtures with activity of the reference catalysts-Fe-Y and HTCo15-800 (d) 


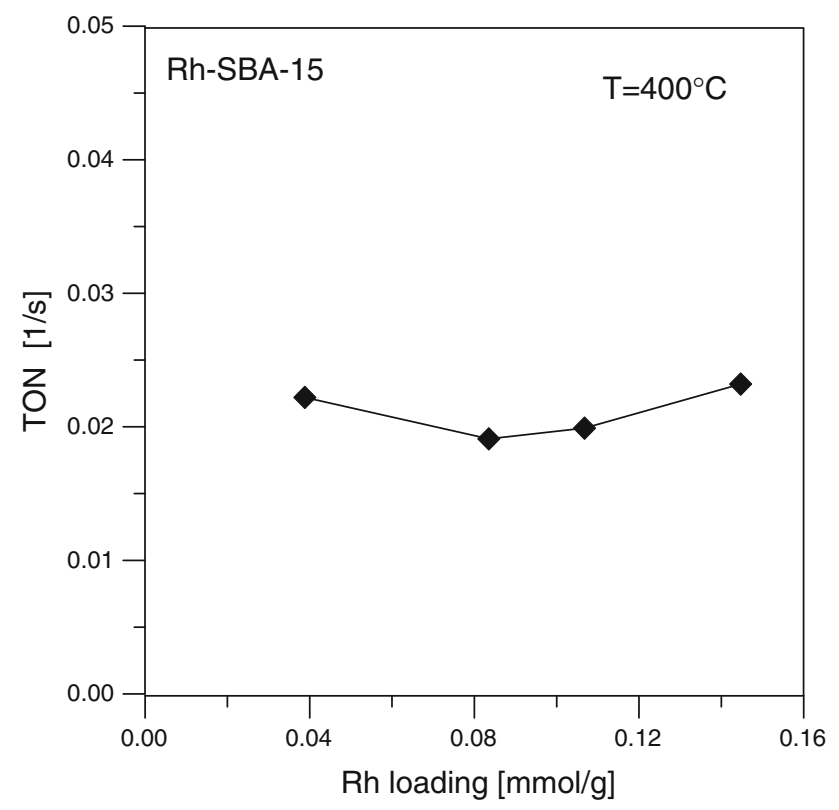

Fig. 10 Turn-over-number $(T O N)$ for decomposition of $\mathrm{N}_{2} \mathrm{O}$ performed at temperature $400{ }^{\circ} \mathrm{C}$ for a series of the $\mathrm{Rh}$-containing catalysts

active component deposited on the silica support (cf. Fig. 5). It should be mentioned, that apart from $\mathrm{N}_{2}$ and $\mathrm{O}_{2}$ no other reaction products were observed.

The values of turn-over-number (TON) determined for the decomposition of $\mathrm{N}_{2} \mathrm{O}$ at temperature of $400{ }^{\circ} \mathrm{C}$ for a series of the catalysts with various loading of rhodium are presented in Fig. 10. It was assumed that each rhodium atom, which is exposed on the catalyst surface (availabile for the $\mathrm{N}_{2} \mathrm{O}$ molecules) plays a role of active site. The number of active sites was determined by oxygen chemisorption. The TON values only slightly depend on the noble metal loading. Therefore, it could be concluded that catalytic activity of rhodium in the form of isolated species as well as small aggregates is very similar. Haber et al. [9] suggested that dispersion of rhodium deposited on $\mathrm{Al}_{2} \mathrm{O}_{3}$ support strongly influenced the activity of the catalysts. However, it should be noted that, in this case, the $\mathrm{Rh}$-dispersion was in the broad range of $15-88 \%$. Probably, in the case of poorly dispersed rhodium, this metal exists in the form of bulky clusters and only part of $\mathrm{Rh}$ atoms is exposed on the surface of the active phase. On the other hand, an application of the MDD method for the deposition of rhodium guaranteed high dispersion of this metal and exposition of majority of $\mathrm{Rh}$ atoms on the catalyst surface.

The results of catalytic tests for the samples containing simultaneously rhodium and aluminium or titanium are shown in Fig. 9b. The deposition of aluminium increased the activity of the SBA-15 based catalyst, while the presence of titanium (Rh-Ti-SBA-15) practically did not influence the catalytic performance of the sample.
Modification of the SBA-15 support with alumina resulted in the formation of both Lewis and Brönsted acidic sites. While, for the Ti-modified silica mainly Lewis centres were found. Therefore, it could be suggested that surface Brönsted acidic sites activate the Rh-containing catalysts in the $\mathrm{N}_{2} \mathrm{O}$ decomposition process. On the other hand, it should be noted that amount of titanium deposited on SBA15 is more than four times higher than aluminium, what resulted in a significant decrease in surface area and pore volume of the Ti-containing sample. Therefore, it seems possible that the limitation of textural parameters is responsible for the lower activity of the Rh-Ti-SBA-15 catalysts.

The activity of the catalysts containing rhodium and copper as well as rhodium and iron was significantly lower than the Rh0.10-SBA-15 sample (Fig. 9c). In this case the formation of catalytically inactive $\mathrm{Rh}-\mathrm{Cu}$ as well as $\mathrm{Rh}-\mathrm{Fe}$ surface species cannot be excluded.

The studies of the influence of water vapour (about 5\%) introduced into the reaction mixture on the catalytic performance of the Rh0.30-SBA-15 sample are presented in Fig. 9d. Introduction of water vapour into the reaction mixture decreased the effectiveness of the $\mathrm{N}_{2} \mathrm{O}$ decomposition process in the presence of this catalyst, however, it should be noted that the activity (measured for the wet reaction mixture) of Rh0.30-SBA-15 is much higher than activity of the reference catalysts- $\mathrm{Co}-\mathrm{Mg}-\mathrm{Al}$ mixed metal oxide (HTCo15-800) and iron modified Y zeolite $(\mathrm{Fe}-\mathrm{Y})$ determined for the dry reaction mixture.

\section{Conclusions}

The Molecular Designed Dispersion method applied for the deposition of metals on SBA-15 resulted in a very high dispersion of the catalytically active components on the support surface. The correlation between the rhodium loading and its dispersion was found. An increase in the Rh loading caused a decrease in its dispersion. Deposition of aluminium and titanium oxides generated acidic sites on the SBA-15 support. For Al-SBA-15 both Lewis and Brönsted acidic sites were found, while Lewis acidic centres dominated in Ti-SBA-15. Copper and iron deposited on the SBA-15 support by the MDD method were present in the form of isolated cations as well as oligomeric metal oxide species.

Rhodium deposited on the SBA-15 support by the MDD method was found to be catalytically active in the $\mathrm{N}_{2} \mathrm{O}$ decomposition process. The catalytic performance depended on the rhodium loading as well as the presence of other metals. An increase in noble metal loading resulted in an activation of the catalysts in the reaction of $\mathrm{N}_{2} \mathrm{O}$ decomposition. Modification of the Rh-containing catalysts with 
aluminium increased its activity, while an opposite effect was observed for the samples modified with copper or iron.

Open Access This article is distributed under the terms of the Creative Commons Attribution Noncommercial License which permits any noncommercial use, distribution, and reproduction in any medium, provided the original author(s) and source are credited.

\section{References}

1. J. Perez-Ramirez, G. Kapteijn, J.A. Moulijn, Appl. Catal. B 44, 117 (2003)

2. A. Takigawa, A. Matsunami, N. Arai, Y.Z. Peng, Energy 30, 475 (2005)

3. R.F. Weiss, J. Geophys. Res. 86, 7185 (1981)

4. G.M. Marnellos, E.A. Efthimiadis, I.A. Vasalos, Appl. Catal. B 46, 523 (2003)

5. E.V. Kondratenko, R. Kraehnert, J. Radnik, M. Baerns, J. PerezRamirez, Appl. Catal. B 298, 73 (2006)

6. J. Oi, A. Obuchi, G.R. Bamwenda, A. Ogata, H. Yagita, S. Kushiyama, K. Mizuno, Appl. Catal. B 12, 277 (1997)

7. S. Tanaka, K. Yuzaki, S. Ito, H. Uetsuka, S. Kameoka, K. Kunimori, Catal. Today 63, 413 (2000)

8. K. Doi, Y.Y. Wu, R. Takeda, A. Matsunami, N. Arai, T. Tagawa, S. Goto, Appl. Catal. B 35, 43 (2001)

9. J. Haber, M. Nattich, T. Machej, Appl. Catal. B 77, 278 (2008)

10. Y. Chen, Y. Huang, J. Xiu, X. Han, X. Bao, Appl. Catal. A 273, 85 (2004)

11. E. Zhao, J. Feng, Q. Huo, N. Melosh, G.H. Fredrickson, B.F. Chmelka, G.D. Stucky, Science 279, 548 (1988)

12. P. Van Der Voort, M. Baltes, E.F. Vansant, J.M.G. White, Interface Sci. 5, 209 (1997)

13. P. Kuśtrowski, L. Chmielarz, R. Dziembaj, P. Cool, E.F. Vansant, J. Phys. Chem. B 109, 11552 (2005)

14. E. Van Bavel, P. Cool, K. Aerts, E.F. Vansant, J. Phys. Chem. B 108, 5263 (2004)
15. L. Chmielarz, P. Kuśtrowski, R. Dziembaj, P. Cool, E.F. Vansant, Appl. Catal. B 62, 369 (2006)

16. Y. Segura, L. Chmielarz, P. Kuśtrowski, P. Cool, R. Dziembaj, E.F. Vansant, Appl. Catal. B 61, 73 (2005)

17. L. Chmielarz, P. Kuśtrowski, R. Dziembaj, P. Cool, E.F. Vansant, Micropor. Mesopor. Mater. 127, 133 (2010)

18. P. Kuśtrowski, L. Chmielarz, R. Dziembaj, P. Cool, E.F. Vansant, J. Phys. Chem. A 109, 9808 (2005)

19. P. Kuśtrowski, L. Chmielarz, J. Surman, E. Bidzińska, R. Dziembaj, P. Cool, E.F. Vansant, J. Phys. Chem. A 109, 330 (2005)

20. J.C. Kenvin, M.G. White, M.B. Mitchell, Langmuir 7, 1198 (1991)

21. L. Chmielarz, P. Kuśtrowski, A. Rafalska-Łasocha, R. Dziembaj, Thermochim. Acta 395, 225-236 (2003)

22. T. Paryjczak, K.W. Jozwiak, J. Goralski, J. Chromatogr. 166, 65 (1978)

23. S.E. Wanke, N.A. Dougharty, J.Catal. 24, 367 (1972)

24. I.V. Babich, Y.V. Plyuto, P. Van Der Voort, E.F. Vansant, J. Coll. Interface Sci. 189, 144 (1997)

25. S. Chylit, L. Haugland, E.A. Blekkan, Micropor. Mesopor. Mater. 111, 134 (2008)

26. R.S. Mulukutla, T. Shido, K. Asakura, T. Kogure, T. Iwasawa, Appl. Catal. A 228, 305 (2002)

27. R.T. Hughes, H.T. White, J. Phys. Chem. 71, 2192 (1967)

28. L. Chmielarz, P. Kustrowski, M. Kruszec, R. Dziembaj, P. Cool, E.F. Vansant, J. Por. Mat. 12, 18 (2005)

29. A.K. Aboul-Gheit, Solid State Ionics 101-103, 893 (1997)

30. D.S. Muggli, J.F. Falconer, J. Catal. 191, 318 (2007)

31. E.P. Parry, J. Catal. 2, 371 (1963)

32. M. Ramakrishna Prasad, G. Kamalakar, S.J. Kulkarni, K.V. Raghavan, J. Mol. Catal. A 180, 109 (2002)

33. S. Velu, K. Suzuki, M. Okazaki, M.P. Kapoor, T. Osaki, F. Ohashi, J. Catal. 194, 373 (2000)

34. M.V. Landau, E. Dafa, L.M. Kaliya, T. Sen, M. Hereskowitz, Micropor. Mesopor. Mater. 49, 65 (2001)

35. R.A. Reimer, S.C. Slaten, M. Seapan, M.W. Lower, P.E. Tomlinson, Environ. Progr. 13, 134 (1994) 